\title{
Effect of Hydrogen on Corrosion and Stress Corrosion Cracking of AZ91 Alloy in Aqueous Solutions
}

\author{
Jian Chen ${ }^{1,2} \cdot$ Jian-Qiu Wang ${ }^{3}$ En-Hou Han ${ }^{3}$ Wei Ke ${ }^{3}$ D. W. Shoesmith ${ }^{1,2}$
}

Received: 16 September 2015/Revised: 14 November 2015/Published online: 4 January 2016

(C) The Chinese Society for Metals and Springer-Verlag Berlin Heidelberg 2015

\begin{abstract}
The effect of hydrogen on the corrosion and stress corrosion cracking of the magnesium AZ91 alloy has been investigated in aqueous solutions. Hydrogen produced by corrosion in water diffuses into, and reacts with the $\mathrm{Mg}$ matrix to form hydride. Some of the hydrogen accumulates at hydride $/ \mathrm{Mg}$ matrix (or secondary phase) interfaces as a consequence of slow hydride formation and the incompatibility of the hydride with the Mg matrix (or secondary phase), and combines to form molecular hydrogen. This leads to the development of a local pressure at the hydride/Mg matrix (or secondary phase) interface. The expansion stress caused by hydride formation and the local hydrogen pressure due to its accumulation result in brittle fracture of hydride. These two combined effects promote both the corrosion rate of the AZ91 alloy, and crack initiation and propagation even in the absence of an external load. Hydrogen absorption leads to a dramatic deterioration in the mechanical properties of the AZ91 alloy, indicating that hydrogen embrittlement is responsible for transgulanar stress corrosion cracking in aqueous solutions.
\end{abstract}

KEY WORDS: AZ91 alloy; Corrosion; Hydrogen; Secondary ion mass spectroscopy (SIMS); Transgulanar stress corrosion cracking (TGSCC)

\section{Introduction}

Hydrogen generation always accompanies the corrosion of magnesium and its alloys in aqueous solutions. With an increase in applied cathodic or anodic potential, the hydrogen generation rate accelerates as a consequence of cathodic polarization or the negative difference effect

Available online at http://link.springer.com/journal/40195

Jian Chen

jchen496@uwo.ca

1 Department of Chemistry, Western University, London, ON N6A 5B7, Canada

2 Surface Science Western, Western University, London, ON N6G 0J3, Canada

3 Key Laboratory of Nuclear Materials and Safety Assessment, Institute of Metal Research, Chinese Academy of Sciences, Shenyang 110016, China
(NDE) [1-21]. Thermodynamically, hydride formation is favorable at a potential less than $-2.3 \mathrm{~V} / \mathrm{SHE}$ in aqueous solutions [22, 23], and magnesium hydride is widely used as a hydrogen storage material [24-27]. Thus, it is inevitable that hydrogen produced by corrosion either directly reacts with magnesium to form corrosion product, as detected using time-of-flight secondary ion mass spectroscopy (ToF-SIMS) [28], X-ray photoelectron spectroscopy (XPS) [29], and X-ray diffraction (XRD) [30, 31], or diffuses into magnesium and its alloys [32-36].

Hydride formation at the film/electrolyte interface will influence the corrosion processes of magnesium and its alloys. According to the $\mathrm{Mg}-\mathrm{H}_{2} \mathrm{O}$ Pourbaix diagram [22, 23 ] and the results of extensive corrosion studies of magnesium and its alloys in aqueous solutions [28-58], it is clear that atomic hydrogen, gaseous hydrogen, and hydride coexist at the film/electrolyte interface. As a consequence of porous corrosion product $\left[\mathrm{Mg}(\mathrm{OH})_{2} / \mathrm{MgO}\right]$ formation [40-42], hydride can decompose into hydroxide and 
hydrogen gas once in contact with water, resulting in a deterioration in film compactness and adherence to the magnesium matrix. Moreover, the abundant hydrogen provided by hydride decomposition and the formation of more porous corrosion products favors hydrogen adsorption and permeation, leading to the acceleration of hydrogen absorption into the magnesium matrix.

This absorbed hydrogen can either be trapped by defects, such as dislocations and grain boundaries, or react with magnesium to form hydride which is thermodynamically stable in the absence of water. Depending on the hydride formation rate, hydride coherence to the matrix, and the diffusion coefficient of hydrogen in magnesium ( $\left.\sim 10^{-9}-10^{-20} \mathrm{~m}^{2} / \mathrm{s}[32-36]\right)$, a presently unknown fraction of the hydrogen might accumulate at the hydride/matrix interface to yield gaseous hydrogen. Thus, a better understanding of the possible hydrogen states in magnesium is required if the role of hydrogen in the corrosion and stress corrosion cracking (SCC) of magnesium and its alloys is to be elucidated.

In this study, the possible states of hydrogen inside the as-cast AZ91 alloy were investigated, and the possible role of hydrogen in corrosion and SCC was discussed. In addition, the correlation between hydride formation and the microstructure of the alloy was also studied.

\section{Experimental}

Experiments were conducted using an as-cast AZ91 magnesium alloy with the composition (wt\%) $9.14 \mathrm{Al}, 0.49 \mathrm{Zn}$, $0.26 \mathrm{Mn},<0.001 \mathrm{Ni}, 0.002 \mathrm{Fe}, 0.002 \mathrm{Cu}$ (balance Mg). The exposed sample surface was ground with silicon carbide papers to a 2000-grit finish, fine polished using $0.5 \mu \mathrm{m}$ diamond paste, cleaned with distilled water and acetone, and then dried in cool air.

For all electrochemical tests, a standard three-electrode system was employed with the as-cast AZ91 alloy as the working electrode, a Pt plate auxiliary electrode, and a saturated calomel reference electrode (SCE). Solutions were prepared using distilled water, and pro-analysis grade $\mathrm{Na}_{2} \mathrm{SO}_{4}$ and $\mathrm{NaOH}$. The experiments were conducted in contact with air at either $20 \pm 2$ or $30 \pm 2{ }^{\circ} \mathrm{C}$, except for experiments performed inside the chamber of an environmental scanning electron microscope (ESEM, $4 \pm 0.1{ }^{\circ} \mathrm{C}$ ).

The mechanically polished samples were cathodically charged in either a $0.1 \mathrm{~mol} / \mathrm{L} \mathrm{Na}_{2} \mathrm{SO}_{4}$ solution $(\mathrm{pH} 6.1$ ) or a $0.1 \mathrm{~mol} / \mathrm{L} \mathrm{NaOH}$ solution $(\mathrm{pH} 13)$ at $14 \mathrm{~mA}$ (the applied cathodic current density was $27.8 \mathrm{~mA} / \mathrm{cm}^{2}$, at an adopted potential of $-4.5 \mathrm{~V}$ ) for $3 \mathrm{~h}$ using a DH1718D-5 Potentiostat. Depending on the experiment to be conducted, the pre-charged samples were treated by one of the following procedures: (1) mechanically polished for $<10$ min using a
$0.5 \mu \mathrm{m}$ oil-based paste (to avoid contact with water), cleaned with acetone, dried in cool air, and immediately analyzed using a CAMECA IMS6F secondary ion mass spectroscopy (SIMS) at an accelerating voltage of $12.5 \mathrm{keV}$ to sputter the surface; (2) vacuum annealed for $2 \mathrm{~h}$ at 150,350 , and $480{ }^{\circ} \mathrm{C}$, respectively, then polished using the oil-based paste, cleaned with acetone, dried in cool air, and analyzed using SIMS; (3) transferred to the chamber of a Philips XL30 ESEM for in situ studies (the experimental procedure has been described in detail elsewhere [42]); (4) used in slow strain rate tests (SSRT) at a strain rate of $1 \times 10^{-6} / \mathrm{s}$. The purpose of the SSRT tests was to study the role of hydrogen in the SCC of the alloy by comparing the SCC behavior of pre-charged to uncharged samples.

The surface and cross-sectional morphologies of these samples were observed using a Phillips XL30 ESEM. X-ray photoelectron spectroscopic (XPS) analyses were carried out on an ESCALAB 250. Spectra were excited using $\mathrm{Al} K_{\alpha}$ radiation to bombard the surface with highenergy monochromatic X-rays $(h v=1486.6 \mathrm{eV})$. Xpspeak 4.1 software was used to analyze the data. Spectra recorded on the thick corrosion product (after $120 \mathrm{~s}$ of ion etching) were corrected for surface charging by setting the carbon $1 s$ peak at $284.6 \mathrm{eV}$.

\section{Results and Discussion}

Typically, the as-cast AZ91 alloy is comprised of $\alpha-\mathrm{Mg}$ grains, $\beta$ phase $\left(\mathrm{Mg}_{17} \mathrm{Al}_{12}\right)$ distributed along grain boundaries, and AlMn precipitates within the $\alpha-\mathrm{Mg}$ grains (Fig. 1) $[35,39-42]$. The Al content of the alloy gradually increases from the $\alpha$-Mg grains to the $\beta$ phase. An in situ ESEM study [45] of the initial corrosion of the AZ91 alloy under a deposited micro-droplet clearly showed that the $\beta$ and AlMn phases are nobler than the $\alpha-M g$ grains based on the distribution of hydrogen generation. Initially, hydrogen

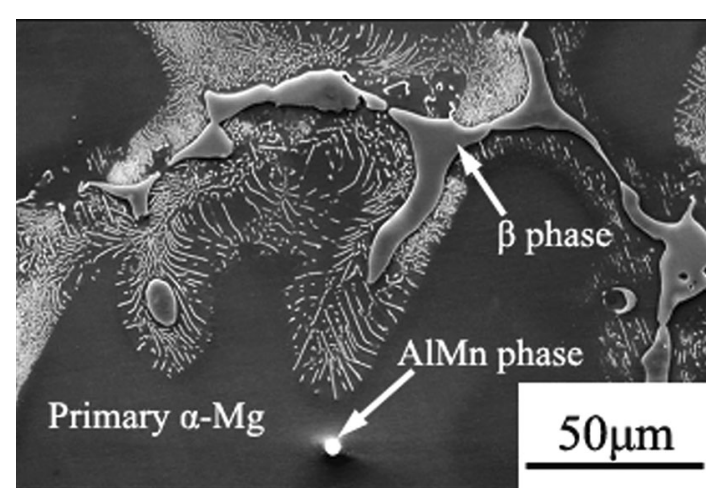

Fig. 1 Microstructure of as-cast AZ91 alloy [39] 
generation distributed mainly around these two phases. However, once corrosion products deposited, the dominant hydrogen generation sites were on the surface of the corrosion products since it is highly possible that porous magnesium hydroxide filled with solution was electronically conductive [59], and that the involvement of Al corrosion products (identified by EDS, XPS, and XRD [35, 37, 39]) increased this conductivity [35, 47]. This indicates that the location of the anodic and cathodic sites on the alloy surface shifted during corrosion as the corrosion products become active cathodic sites. These galvanic couples would provide abundant hydrogen at the film/electrolyte interface, which is the prerequisite for hydrogen permeation.

If hydrogen generation can only occur on the substrate $\mathrm{Mg}$ surface in contact with the solution in the surface film pores as suggested by Song and Unocic [60], the hydrogen generation rate should be (at least partially) limited by hydrogen transport in the pores once the corrosion product film became thick at long exposure time. In addition, coverage by corrosion products would decrease the effective corroding surface area. These two factors would lead to a slowdown of the hydrogen generation rate at longer immersion times, which is the opposite of the hydrogen collection results presented by Song and Unocic [60]. The deposition of corrosion products on the Mg surface would lead to a separation of anodes and cathodes with the proportion of the cathodic area increasing, which is in agreement with the results of SVET (scanning vibrating electrode technique) [61].

\subsection{Cracking of $\beta$ Phase in AZ91 Alloy}

Studies [35, 39] showed that the $\beta$ phase in AZ91 experienced brittle fracture after immersion in a $0.1 \mathrm{~mol} / \mathrm{L} \mathrm{Na}_{2}$ $\mathrm{SO}_{4}$ solution for $480 \mathrm{~h}$ under natural corrosion conditions (Fig. 2a). After cathodic charging at a current density of $27.8 \mathrm{~mA} / \mathrm{cm}^{2}$ in a $0.1 \mathrm{~mol} / \mathrm{L} \mathrm{Na}_{2} \mathrm{SO}_{4}$ solution for $3 \mathrm{~h}$, and the removal of the $\mathrm{Mg} / \mathrm{Al}$ hydroxides (detected by XPS), the $\beta$ phase was observed to be cracked. Examination of a cross section, Fig. 2 b, clearly showed that more cracks were present in the pre-charged sample than that in the one only exposed to the sulfate solution. These results suggest that hydrogen produced by either corrosion or cathodic polarization can lead to brittle fracture of the $\beta$ phase in the alloy. To investigate the consequences of absorbed hydrogen on the corrosion behavior of the AZ91 alloy, the pre-charged specimen was fine polished like the uncharged one and subsequently exposed to a fresh $0.1 \mathrm{~mol} / \mathrm{L} \mathrm{Na}_{2} \mathrm{SO}_{4}$ solution for $4 \mathrm{~h}$ under natural corrosion conditions. Subsequent examination of a cross section showed that the average thickness of corrosion products deposited on the pre-charged sample after this exposure was $\sim 20 \mu \mathrm{m}$ (Fig. 2c), which was twice the thickness of the layer formed on an uncharged sample exposed for $181 \mathrm{~h}$ under the same conditions $(\sim 10 \mu \mathrm{m}$ [39]). This difference showed that the absorbed hydrogen greatly accelerated the corrosion process.

When the pre-charged sample was transferred into the ESEM chamber and covered with a thin layer of solution, the hydrogen produced by corrosion was observed to permeate into the alloy, leading to the initiation of additional cracks as well as the propagation of existing ones [42].

\subsection{Hydrogen State in AZ91 Alloy}

After cathodic charging, the distribution of hydrogen was immediately determined by SIMS which showed that the hydrogen content around the $\beta$ phase was relatively higher than that in other regions [35].

As discussed in the introduction, there are three possible states of hydrogen absorbed into the alloy: atomic hydrogen, hydride, and molecular hydrogen. Previous study on the effects of hydrogen on the mechanical properties of iron and steel [62] showed that trapped hydrogen could be
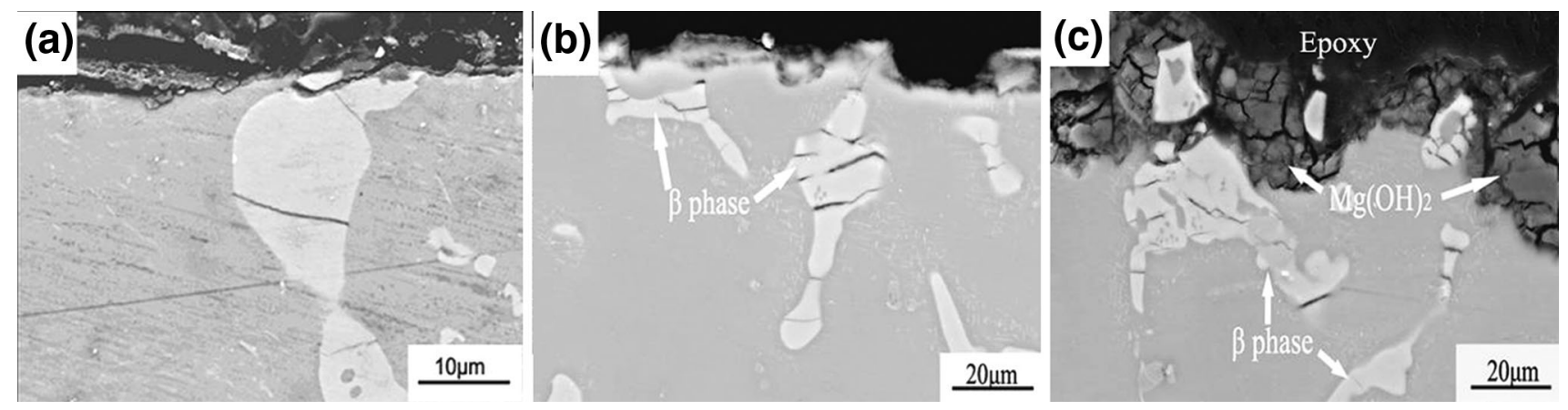

Fig. 2 Cross sections of as-cast AZ91 magnesium alloy: a after immersion in $0.1 \mathrm{~mol} / \mathrm{L} \mathrm{Na}_{2} \mathrm{SO}_{4}$ solution under natural corrosion condition for $480 \mathrm{~h}, \mathbf{b}$ after cathodic charging in $0.1 \mathrm{~mol} / \mathrm{L} \mathrm{Na}_{2} \mathrm{SO}_{4}$ solution at $27.8 \mathrm{~mA} / \mathrm{cm}^{2}$ for $3 \mathrm{~h}, \mathbf{c}$ after cathodic charging in $0.1 \mathrm{~mol} / \mathrm{L} \mathrm{Na}_{2} \mathrm{SO}_{4}$ solution at $27.8 \mathrm{~mA} / \mathrm{cm}^{2}$ for $3 \mathrm{~h}$ and then immersion in fresh $0.1 \mathrm{~mol} / \mathrm{L} \mathrm{Na}_{2} \mathrm{SO}_{4}$ solution under natural corrosion condition for $4 \mathrm{~h}$ [35] 
released after annealing once the characteristic energy of traps (both reversible and irreversible) was reached. Hydride is thermodynamically stable when the annealing temperature is less than its decomposition temperature, but decomposes to produce abundant hydrogen and a very high local hydrogen pressure when the annealing temperature is higher than the hydride decomposition temperature. This leads to crack initiation and propagation in the alloy. Theoretically, the hydride decomposition temperature is $281.9{ }^{\circ} \mathrm{C}$ [63], while the measurements show it to be in the range of $250-438{ }^{\circ} \mathrm{C}$ [64-66]. Chakrapani and Pugh [67] showed that the hydrogen concentration in $\mathrm{Mg}$ samples corroded in $\mathrm{NaCl} / \mathrm{K}_{2} \mathrm{CrO}_{4}$ solution for $24 \mathrm{~h}$ decreased from $\sim 170$ to $\sim 50 \mathrm{ppm}$ after vacuum annealing at $385{ }^{\circ} \mathrm{C}$ for $4 \mathrm{~h}$. This suggested that trapped hydrogen was mostly released at that annealing temperature while the hydride decomposition temperature should be $>385{ }^{\circ} \mathrm{C}$. Thus, samples were treated at three annealing temperatures, 150 , 350 , and $480{ }^{\circ} \mathrm{C}$, to identify the presence of hydride within the alloy based on whether or not cracks were seen on the surface. According to $\mathrm{Mg}-\mathrm{Al}$ and $\mathrm{Mg}-\mathrm{Zn}$ binary phase diagrams [68], it is impossible that cracks caused by locally melted alloy solidification would be present during these annealing treatments.

The typical surface morphologies of the annealed samples are shown in Fig. 3. Generally, the crack length increased with increasing annealing temperature. After annealing at $150{ }^{\circ} \mathrm{C}$, the crack length (in Fig. 3a) was similar to that after cathodic charging, Fig. 2b. When the annealing temperature increased to $350{ }^{\circ} \mathrm{C}$, the crack in the $\beta$ phase was longer than the one caused by annealing at $150{ }^{\circ} \mathrm{C}$ (Fig. 3b). After annealing at $480{ }^{\circ} \mathrm{C}$, which is higher than the hydride decomposition temperature, many intergranular cracks were observed (Fig. 3c), indicating the presence of hydride within the alloy. This places the hydride decomposition temperature within the range from 350 to $480{ }^{\circ} \mathrm{C}$, which is consistent with the results of Chakrapani and Pugh [67].

The location of these intergranular cracks suggested that hydride formation was strongly related to the distribution of $\beta$ phase. Compared to the crack length after annealing at
$150{ }^{\circ} \mathrm{C}$, the increased crack length in the sample annealed at $350{ }^{\circ} \mathrm{C}$ suggested a change in the physical properties of hydrogen (such as volume) inside the alloy could be responsible for the observed crack growth, since the hydride is stable at this annealing temperature. One possibility is that the molecular hydrogen accumulated at hydride/ $\mathrm{Mg}$ interfaces within the matrix expanded during annealing to produce a local pressure, causing crack initiation, and propagation.

SIMS analyses of $\mathrm{H}$ and $\mathrm{Al}$ were used to confirm the relationship between the site of hydride formation and the microstructure of the AZ91 alloy. After annealing at $150{ }^{\circ} \mathrm{C}$, partial trapped hydrogen may be released, but the hydride would remain dormant in the interior of the alloy. Figure 4 shows the distribution of hydrogen and $\mathrm{Al}$ after annealing at $150{ }^{\circ} \mathrm{C}$, with the $\mathrm{Al}$ distribution indicating the location of the $\beta$ phase. It is clear that hydride was located in the $\beta$ phase (Fig. 4a, b), in accordance with the crack initiation sites shown in Figs. 2 and 3. After annealing at $480{ }^{\circ} \mathrm{C}$, hydrogen enrichment was still detected at the front of the crack tip (Fig. 4c, d). There are two possible explanations for this: (1) The characteristic energy of some hydrogen traps was quite high; (2) since the diffusion coefficient of hydrogen in magnesium at $480{ }^{\circ} \mathrm{C}$ is high ( $\sim 10^{-7} \mathrm{~m}^{2} / \mathrm{s}$ [69]) and hydride decomposition releases abundant hydrogen, hydrogen becomes enriched at defects in front of the crack tip to reform molecular hydrogen.

If hydrogen gas can form in the interior of the alloy, it should be much easier to accumulate and form blisters near the surface, as observed for $\mathrm{Zn}$ [70], steel [71], and W [72]. In aggressive sulfate solutions, hydrogen absorption accelerated the corrosion rate of the alloy (Fig. 2), suggesting it is hard for hydrogen blisters to form near the surface of the alloy under these conditions. However, we showed previously [48] that the AZ91 alloy is passive in alkaline solution ( $\mathrm{pH}$ 13), making this a possible medium for hydrogen blister formation. To accelerate the hydrogen permeation process, the AZ91 alloy was cathodically polarized at the same current density used in the sulfate solution. Figure 5a shows that hydrogen blisters are formed
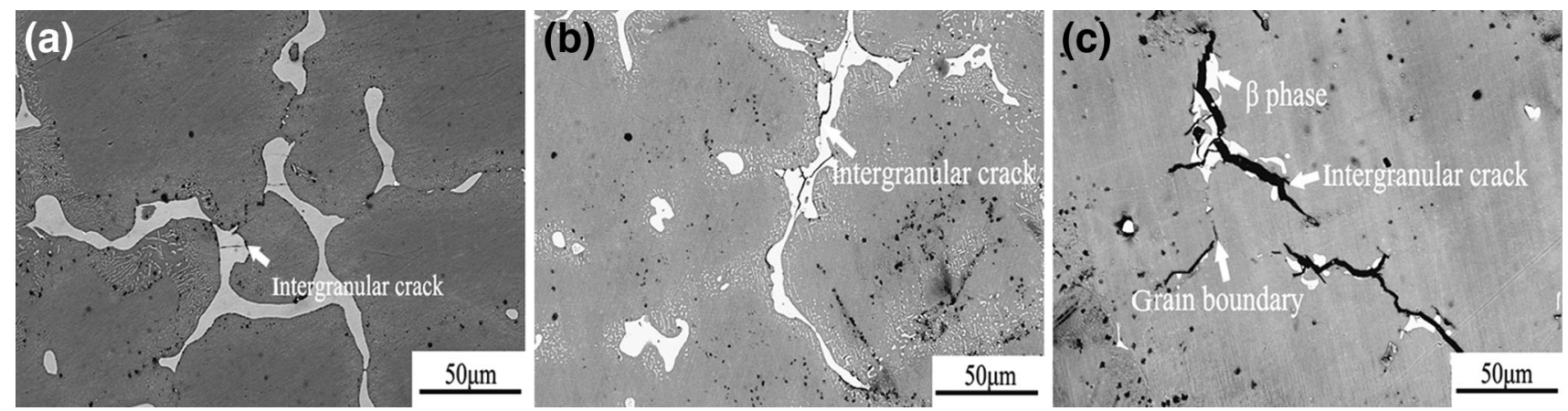

Fig. 3 Surface morphology of the pre-charged AZ91 alloy after vacuum annealing at: a $150{ }^{\circ} \mathrm{C}, \mathbf{b} 350{ }^{\circ} \mathrm{C}, \mathbf{c} 480{ }^{\circ} \mathrm{C}[35]$ 

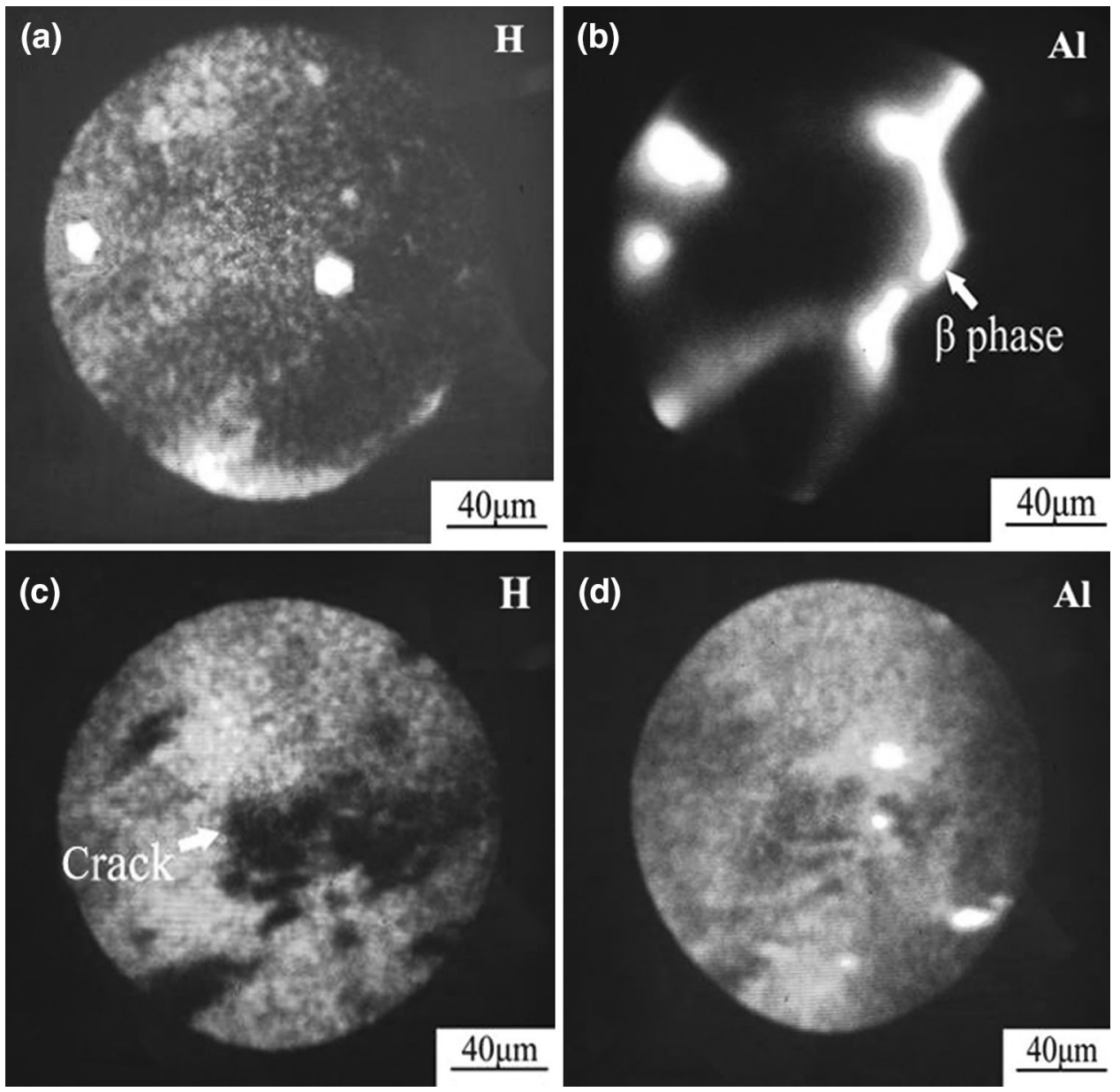

Fig. 4 Element mapping of the pre-charged AZ91 alloy using SIMS: $\mathrm{H}$ mapping $\mathbf{a}$, Al mapping $\mathbf{b}$ after vacuum annealing at $150{ }^{\circ} \mathrm{C}, \mathrm{H}$ mapping c, Al mapping d after vacuum annealing at $480{ }^{\circ} \mathrm{C}[35]$

on the alloy surface, confirming that molecular hydrogen is one of the hydrogen states inside the alloy. Once a critical hydrogen pressure was reached, the blister ruptured, leading to the initiation of many cracks around the broken blister (Fig. 5b).

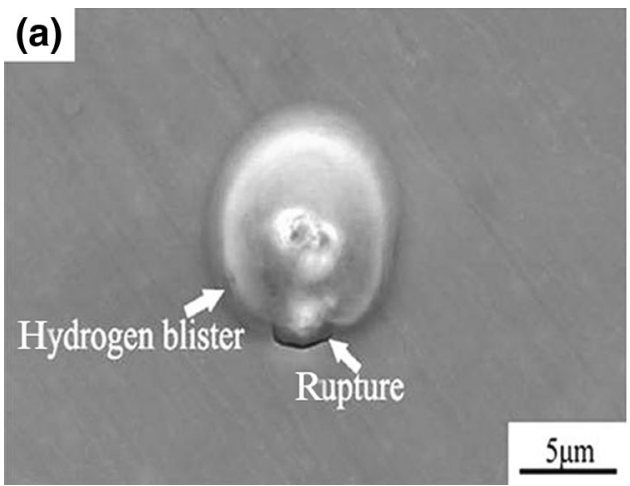

It can be concluded that hydrogen produced by either corrosion or cathodic polarization diffused into the alloy and reacted with $\mathrm{Mg}$ to form hydride. Since hydrogen diffusion was faster than the rate of hydride formation, and hydride needs to form as a separate phase within the $\mathrm{Mg}$

Fig. 5 Surface morphology of as-cast AZ91 magnesium alloy after cathodic charging in $0.1 \mathrm{~mol} / \mathrm{L} \mathrm{NaOH}$ solution at $27.8 \mathrm{~mA} / \mathrm{cm}^{2}$ for a $1 \mathrm{~h}$, b $3 \mathrm{~h}[50]$ 
matrix (or $\beta$ phase), the hydrogen accumulated at the hydride/Mg matrix (or $\beta$ phase) interface combined to form gas. When the pressure caused by hydrogen gas formation, and hydride formation and expansion, reached a critical value, the hydride in the $\mathrm{Mg}$ matrix (or $\beta$ phase) experienced brittle fracture, leading to crack initiation (Fig. 2). Thus, the main hydrogen states inside the alloy are trapped atomic hydrogen, hydride, and accumulated hydrogen gas at the hydride/Mg matrix (or $\beta$ phase) interface.

\subsection{Hydrogen Effect on SCC of AZ91 Alloy}

When the AZ91 alloy was exposed to a gaseous hydrogen atmosphere, its tensile properties (i.e., ultimate tensile strength) and ductility (i.e., elongation) dramatically decreased compared to that exposed in $\mathrm{Ar}$ and air [73]. This is in accordance with our previous study [43]. With increasing pre-exposure time in gaseous hydrogen, a more serious degradation in mechanical properties occurred. This indicates hydrogen, regardless of its source (e.g., by either corrosion, cathodic charging, or absorption from a gaseous atmosphere), is responsible for the decrease in mechanical properties.

In aqueous solutions, the AZ91 alloy is inherently susceptible to TGSCC $[42-44,47,49,69,73-77]$. For example, even when the alloy was exposed to distilled water, the mechanical properties of the alloy were much lower than that exposed to air. Cross-sectional and fractographical observations showed the initiation of many transgranular secondary cracks in the $\beta$ phase $[43,73]$. In a more aggressive $\mathrm{Na}_{2} \mathrm{SO}_{4}$ solution, the tensile and ductile properties of both the pre-charged and uncharged alloy decreased to half of the values for the uncharged alloy tested in air [43], and more transgranular cracks initiated in the $\beta$ phase ahead of the main crack [43]. In the presence of an external load, the main crack propagated by interlinking these minor cracks leading to fracture. These results suggest that the hydrogen produced by either corrosion or cathodic charging contributes to the TGSCC of the AZ91 alloy, and the hydrogen embrittlement (HE) is the main TGSCC mechanism.

Figure 2 clearly shows that the $\beta$ phase in AZ91 can crack during corrosion or cathodic charging, and the existing crack in the $\beta$ phase can propagate in the absence of an external load [42]. This can be attributed to hydride formation and hydrogen gas accumulation. The longer the pre-exposure time to gaseous hydrogen and the cathodic pre-charging time, the easier the initiation and propagation of the cracks, and also the degradation in mechanical properties. In the presence of an external load, the corrosion films were easily ruptured, which favoured hydrogen adsorption and permeation. Since the stress and concentration gradient are the driving forces for hydrogen diffusion $[49,75]$, hydrogen transport inside the alloy was faster than that in the absence of an external load. This suggests the initiation of more cracks and a further deterioration in mechanical properties.

\section{Conclusions}

1. Atomic hydrogen, hydride, and molecular hydrogen are the main hydrogen states inside the AZ91 alloy.

2. The $\beta$ phase in the alloy experienced brittle cracking during either corrosion or cathodic charging, and existing cracks in the $\beta$ phase can propagate in the absence of an external load.

3. The expansion stress due to hydride formation and the pressure developed by hydrogen gas accumulation are responsible for crack initiation and propagation in the $\beta$ phase.

4. The absorption of hydrogen produced by either corrosion or cathodic polarization, or adsorbed from the gaseous phase results in the deterioration of the mechanical properties of the alloy.

5. HE is the main mechanism for TGSCC of the AZ91 alloy in aqueous solutions.

Acknowledgments The work is supported by the Hundred Talent Program of the Chinese Academy of Sciences, the National Natural Science Foundation of China (No. 50499336), and the National Basic Research Program of China (No. 2007CB613705).

\section{References}

[1] W. Beetz, Philos. Mag. 4, 269 (1866)

[2] R.L. Petty, A.J. Davidson, J. Kleinberg, J. Am. Chem. Soc. 76, 363 (1954)

[3] M.D. Rausch, W.E. McEwen, J. Kleinberg, J. Am. Chem. Soc. 76, 3622 (1954)

[4] M.D. Rausch, W.E. McEwen, J. Kleinberg, J. Am. Chem. Soc. 77, 2093 (1955)

[5] J.H. Greenblatt, J. Electrochem. Soc. 103, 539 (1956)

[6] M.D. Rausch, W.E. McEwen, J. Kleinberg, Chem. Rev. 57, 417 (1957)

[7] M.E. Straumanis, J. Electrochem. Soc. 105, 284 (1958)

[8] J.L. Robinson, P.F. King, J. Electrochem. Soc. 108, 36 (1961)

[9] M.E. Straumanis, B.K. Bhatia, J. Electrochem. Soc. 110, 357 (1963)

[10] P.F. King, J. Electrochem. Soc. 113, 536 (1966)

[11] W.J. James, M.E. Straumanis, J.W. Johnson, Corrosion 23, 15 (1967)

[12] J.W. Johnson, C.K. Chi, W.J. James, Corrosion 23, 204 (1967)

[13] T. Przyluski, E. Palka, Electrochim. Acta 15, 8337 (1970)

[14] R. Tunold, H. Holtan, M.-B. Hagg Berge, A. Lasson, R. SteenHansen, Corros. Sci. 17, 353 (1977)

[15] R.S. Stampella, R.P.M. Procter, V. Ashworth, Corros. Sci. 17, 325 (1984)

[16] G.L. Song, A. Atrens, D. St. John, J. Nairn, Y. Li, Corros. Sci. 39, 855 (1997) 
[17] G.L. Song, A. Atrens, M. Dargusch, Corros. Sci. 41, 249 (1998)

[18] G.L. Song, A. Atrens, Adv. Eng. Mater. 1, 11 (1999)

[19] G.L. Song, A. Atrens, Adv. Eng. Mater. 5, 837 (2003)

[20] M.C. Zhao, M. Liu, G.L. Song, A. Atrens, Corros. Sci. 50, 1939 (2008)

[21] G.L. Song, Corros. Sci. 51, 2063 (2009)

[22] G. Perrault, J. Electroanal. Chem. 51, 107 (1974)

[23] J. Chen, J.H. Dong, J.Q. Wang, E.-H. Han, W. Ke, Corros. Sci. 50, 3610 (2008)

[24] J.F. Stampfer, C.E. Holley, J.F. Suttle, J. Am. Chem. Soc. 82, 3504 (1960)

[25] A. San-Martin, F.D. Manchester, J. Phase Equilib. 8, 431 (1987)

[26] H. Okamoto, J. Phase Equilib. Diffus. 22, 598 (2001)

[27] B. Sakintuna, F. Lamaridarkrim, M. Hirscher, Int. J. Hydrogen Energy 32, 1121 (2007)

[28] S. Antoine, M. Liu, P. Schmutz, G.L. Song, A. Atrens, P. Marcus, Corros. Sci. 51, 1883 (2009)

[29] M. Liu, S. Zanna, H. Ardelean, I. Frateur, P. Schmutz, G. Song, A. Atrens, P. Marcus, Corros. Sci. 51, 1115 (2009)

[30] E. Gulbrandsen, Electrochim. Acta 37, 1403 (1992)

[31] E. Gulbrandsen, J. Tafto, A. Olsen, Corros. Sci. 34, 1423 (1993)

[32] G.L. Makar, J. Kruger, K. Sieradzki, Corros. Sci. 34, 1311 (1993)

[33] P. Spatz, H.A. Aebiseher, A. Krozer, L. Schlapbach, Z. Phys. Chem. 181, 393 (1993)

[34] A. Atrens, N. Winzer, G. Song, W. Dietzel, C. Blawert, Adv. Eng. Mater. 8, 749 (2006)

[35] J. Chen, J.Q. Wang, E.-H. Han, J.H. Dong, W. Ke, Corros. Sci. 50, 1292 (2008)

[36] W. Dietzel, M. Pfuff, N. Winzer, Eng. Fract. Mech. 77, 257 (2010)

[37] J. Chen, J.Q. Wang, E.-H. Han, J.H. Dong, W. Ke, Mater. Corros. 57(10), 789 (2006)

[38] J. Chen, J.Q. Wang, E.-H. Han, W. Ke, Mater. Sci. Forum 546-549, 537 (2007)

[39] J. Chen, J.Q. Wang, E.-H. Han, J.H. Dong, W. Ke, Electrochim. Acta 52, 3299 (2007)

[40] J. Chen, J.Q. Wang, E.-H. Han, W. Ke, Corrosion 63(7), 661 (2007)

[41] J. Chen, J.Q. Wang, E.-H. Han, W. Ke, Corros. Sci. 49(3), 1625 (2007)

[42] J. Chen, J.Q. Wang, E.-H. Han, W. Ke, Corros. Sci. 50, 2338 (2008)

[43] J. Chen, J.Q. Wang, E.-H. Han, W. Ke, Mater. Sci. Eng. A 488(1-2), 428 (2008)

[44] J.Q. Wang, J. Chen, E.-H. Han, W. Ke, Mater. Trans. 49(5), $1052(2008)$

[45] J. Chen, J.Q. Wang, E.-H. Han, W. Ke, Electrochem. Commun. 10, 577 (2008)

[46] J. Chen, J.Q. Wang, E.-H. Han, W. Ke, Corros. Sci. 50(5), 1449 (2008)

[47] J. Chen, J.Q. Wang, E.-H. Han, W. Ke, Mater. Sci. Eng. A 494, 257 (2008)

[48] J. Chen, J.Q. Wang, E.-H. Han, W. Ke, Corros. Sci. 51, 477 (2009)

[49] J. Chen, M.R. Ai, J.Q. Wang, E.-H. Han, W. Ke, Mater. Sci. Eng. A 515, 79 (2009)

[50] J. Chen, M.R. Ai, J.Q. Wang, E.-H. Han, W. Ke, Corros. Sci. 51, $1197(2009)$
[51] F. Huang, J. Chen, J.Q. Wang, J. Chin. Soc. Corros. Prot. 30(5), 347 (2010). (in Chinese)

[52] J. Chen, J.Q. Wang, E.-H. Han, W. Ke, Corros. Eng. Sci. Technol. 46(3), 277 (2011)

[53] Y.W. Song, D.Y. Shan, R.S. Chen, E.-H. Han, Corros. Sci. 51, 1087 (2009)

[54] Y.W. Song, D.Y. Shan, R.S. Chen, E.-H. Han, Corros. Sci. 52, 1830 (2010)

[55] Y.W. Song, E.-H. Han, D.Y. Shan, C.D. Yim, B.S. You, Corros. Sci. 60, 238 (2012)

[56] Y.W. Song, E.-H. Han, D.Y. Shan, C.D. Yim, B.S. You, Corros. Sci. 65, 322 (2012)

[57] S.D. Wang, D.K. Xu, X.B. Chen, E.-H. Han, C. Dong, Corros. Sci. 92, 228 (2015)

[58] R.C. Zeng, Y. Hu, S.K. Guan, H.Z. Cui, E.-H. Han, Corros. Sci. 86, 171 (2014)

[59] J. Gasc, F. Brunet, N. Bagdassarov, V. Morales-Flórez, Phys. Chem. Miner. 38(7), 543 (2011)

[60] G.L. Song, K.A. Unocic, Corros. Sci. 98, 758 (2015)

[61] G. Williams, N. Birbilis, H.N. McMurray, Eelectrochem. Commun. 36, 1 (2013)

[62] J.P. Hirth, Metall. Trans. A 11, 861 (1980)

[63] T. Reed, Free Energy Binary Compounds (MIT Press, Cambridge, 1971)

[64] F. Gennari, G. Urretavizacya, Lat. Am. Appl. Res. 32(4), 275 (2002)

[65] A. Andreasen, Properties of $M g-A l$ Alloys in Relation to Hydrogen Storage (Ris $\varnothing$ National Laboratory, Denmark, 2005), p. 11

[66] R. Schulz, G. Liang, J. Huot, in Proceedings of the 22nd Ris $\phi$ International Symposium on Material Science: Science of Metastable and Nanocrystalline Alloys Structure, Properties and Modelling, ed. by A. Dinesen, M. Eldrup, D. Juul Jensen, S. Lindesoth, T. Pedersen, N. Pryds, A. Pedersen, J. Wert (Roskilde, Denmark, 2001)

[67] D. Chakrapani, E. Pugh, Metall. Trans. A 6, 173 (1975)

[68] T.B. Massalski, H. Okamoto, Binary Alloys Phase Diagrams, 2nd edn. (ASM, Metal Park, 1990), p. 574

[69] A. Atrens, W. Dietzel, P. Srinivasan, N. Winzer, M. B. Kannan, Stress corrosion cracking:Theory and practice, ed. by V.S. Raja, T. Shoji (Woodhead, Oxford, 2011), pp. 341-380

[70] S. Amami, C. Lemaitre, A. Laksimi, S. Benmedakhene, Corros. Sci. 52(5), 1705 (2010)

[71] G. Domizzi, G. Anteri, J. Ovejero-Garcia, Corros. Sci. 43, 325 (2001)

[72] Y. Ueda, T. Funabiki, T. Shimada, K. Fukumoto, H. Kurishita, M. Nishikawa, J. Nucl. Mater. 337, 1010 (2005)

[73] N. Winzer, A. Atrens, W. Dietzel, V.S. Raja, G. Song, K.U. Kainer, Mater. Sci. Eng. A 488, 339 (2008)

[74] N. Winzer, A. Atrens, W. Dietzel, G. Song, K.U. Kainer, JOM 59, 49 (2007)

[75] N. Winzer, A. Atrens, W. Dietzel, G. Song, K.U. Kainer, Adv. Eng. Mater. 10, 453 (2008)

[76] N. Winzer, A. Atrens, W. Dietzel, G. Song, K.U. Kainer, Mater. Sci. Eng. A 472, 97 (2008)

[77] N. Winzer, A. Atrens, W. Dietzel, G. Song, K.U. Kainer, Mater. Sci. Eng. A 466, 18 (2007) 